Research Article

\title{
Geospatial model for establishing constructed wetlands for municipal waste water treatment: Case study in South Bačka District, Serbia
}

\author{
Jasna Grabić, Sanja Antić*, Pavel Benka, Boško Blagojević \\ University of Novi Sad, Faculty of Agriculture, Departmet of Water Management, Serbia
}

Article Details: Received:2020-12-31 ｜ Accepted: 2021-03-08 | Available online: 2021-05-31

(c) $(1) \ominus$ Licensed under a Creative Commons Attribution 4.0 International License

The process of integration into the European Union (EU) requires from new member states significant efforts; not only harmonizing legislation but also respecting all posed standards. Among numerous issues, wastewater purification represents a significant request. To achieve the goal of discharging good-quality water into natural water bodies as recipients, various methods have been used. The method of constructed wetland (CW) is based on wastewater purification by using wetland plants. The method of CWs shows the best results for small settlements for up to 5,000 inhabitants and can be nicely integrated within the landscape of a plain where waterbodies' banks are overgrown by wetland plants. Such facilities have been used for decades in the territory of the EU, and only a few have been built in the Republic of Serbia. Since the Republic of Serbia is a candidate country for the EU, there is a strong intention to take action focused upon solving wastewater purification from various sources. Therefore, this paper aims to examine favourable locations for CW installations within the rural area of the South Bačka District. Geographic information system was applied for examination of the basic spatial criteria (distance from the settlement, distance from water bodies, elevation, and land use). These were presented in separate maps and finally in one joint map of favourability for establishing CWs in the vicinity of 35 villages within the District. The obtained results have fulfilled the basic spatial preconditions, but further analyses should be conducted to precisely position the location of each CW concerning land ownership criterion.

Keywords: wastewater treatment, constructed wetland, geographic information system - GIS, South Bačka District

\section{Introduction}

Natural ecosystems are dependent on water, but also ecology and landscape influence water quality and availability (González et al., 2013). The practice of releasing non-purified water into water bodies leads to deterioration of water quality, eutrophic processes (algal blooms), and might have a significant impact on biodiversity. Until now humans have significantly affected water quality and quantity and therefore the goal of ensuring availability and sustainable management of water and sanitation for all is listed on the 6th place in the UN's "The 2030 Agenda for Sustainable Development" (United Nations, 2015). Due to the overall importance of water and its multipurpose use, it has special protection by a set of regulations under the umbrella of Water Framework Directive - WFD (Directive 2000/60/EC, 2000) in the territory of the EU, which is the most important legal instrument in the field of water in the European Union. Concerning wastewater treatment (WWT), its daughter directive Council Directive 91/271/EEC on urban wastewater treatment, is in charge, while some specific pollutants are covered by the Directive 2013/39/ EU (2013), regarding priority substances. The method of constructed wetlands (CWs) as a solution for WWT is well known and has wide applicability (Vymazal, 2005). In recent years upon enacting the Directive 2013/39/ EU (2013) regarding priority substances in the field of water policy, the role of CWs was also examined (Gorito et al., 2017), but further research is necessary. Currently, when green technologies are taking advantage and in the context of promoting the circular economy, reconnecting urban environment with nature, CWs are seen as a promising solution. Besides water, purification CWs can provide other services such as habitat creation sites, urban wildlife refuges, recreational or educational facilities, landscape engineering, etc. (Stefanakis, 2019).

Harmonizing with the WFD and later on respecting standards posed by its daughter directives is one of the

\footnotetext{
*Corresponding Author: Sanja Antić, University of Novi Sad, Faculty of Agriculture, Trg D. Obardovića 8, 21000 Novi Sad, Serbia; e-mail: sanja.antic@polj.uns.ac.rs
} 
core questions for both members and candidate states. Presently, there is a lack of WWT facilities in Serbia. Therefore, it i imperative for the country, on its way toward joining the EU to provide wastewater purification for all pollution sources (Kolaković et al., 2013; SEPA, 2019). It is necessary to treat wastewater as close as possible to the place of origin which for small settlements excludes large, centralized treatment systems. Besides the conventional method of WWT, CW represents a favourable solution for small settlements for up to 5,000 inhabitants. CWs have been in use for decades worldwide and in Serbia from 2004, when the first CW was established (Josimov-Dundjerski et al., 2013, 2015a). Northern Serbia (Vojvodina Province) has been characterized by flat land, being a part of the Pannonian Plain. Numerous water bodies intersect the plain consisting of rivers and drainage canals, as well as natural wetlands adjacent to river meanders, or formed from abandoned meanders. In such a landscape, common reed (Phragmites australis (Cav.) Trin. ex Steud.) builds dense stands along riverbeds. Especially, it covers large areas of wetlands, where it represents dominant vegetation. Bearing this in mind CWs are leading nature-based solutions for wastewater purification. Another important fact is that in the Northern Serbia - Vojvodina Province the dominant type of settlements are villages with up to 5,000 inhabitants (Josimov-Dunđerski et al., 2015b), relatively uniformly dispersed within the landscape, where centralized systems are not an appropriate solution.

The paper aims to select favourable locations for CW installations intended for settlements within the rural area of the South Bačka District. During the examination, the most important spatial criteria were analyzed.

\section{Material and methods}

\subsection{Study area}

The research area in this paper encompassed the South Bačka District (Fig. 1). The area is characterised by flat land, mostly cultivated as arable land. Besides, an important feature is a dense hydrographic network consisting of artificial drainage canals, which join rivers. Small settlements - villages are the dominant type of settlements and are relatively uniformly dispersed over the District. The average number of inhabitants for 35 examined settlements was 2,485, while minimum and maximum were 738 and 4,831, respectively (Statistical Office of the Republic of Serbia, 2014). The overall population of the South Bačka District according to the census from 2011 was 86968 inhabitants. This assumes the production of $13,045 \mathrm{~m}^{3}$ of wastewater daily, if calculated as 150l/day per inhabitant equivalent (Dalmacija, 2010).

\subsection{Constructed wetlands}

The primary function of CWs is wastewater purification. Wastewater can originate from various sources: municipal, industrial, agriculture, etc. The cores of CWs are wetland plants, which are intentionally planted and irrigated by wastewater. Typical plants of CWs are common reed (Phragmites australis) and rush (Typha angustifolia). Plants feed on nutrients available in

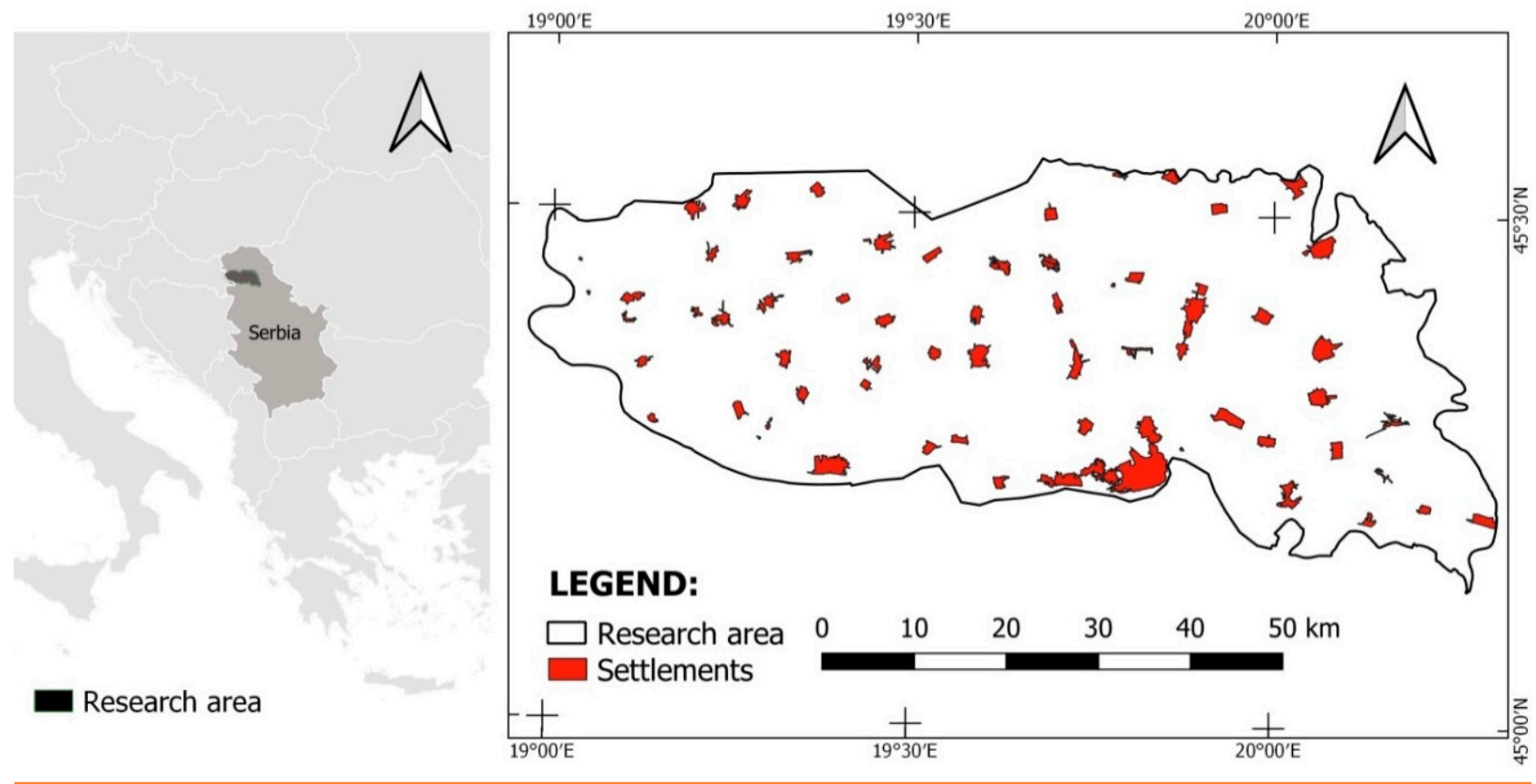

Figure 1 Location of investigated area - the South Bačka District, Republic of Serbia 
wastewater and provide oxygen to the root zone. They also enable microorganisms from rhizosphere to conduct nitrification and other processes of degrading organic molecules from wastewater making them available to plants. Additionally, plants absorb and bioaccumulate heavy metals and other toxic compounds (Nikolić et al., 2015). Each CW is composed of several segments/fields which have an impermeable bottom. The segments are placed in line and wastewater flows from one field to another until the end. At the outlet, water is purified up to a level posed by wastewater quality standards. The efficiency of purification depends on a type of CW and can be above $80-90 \%$ for total nitrogen, total phosphorus, BOD, COD, and total suspended solids (Vymazal, 2005).

The Pannonian part of Serbia, the Vojvodina Province, is characterized by a flat landscape intersected by the dense hydrographic network. Wetland plants overgrow edges of watercourses and shallow marshy areas, all forming dense uniform stands, providing nesting places for birds and shelter for other organisms. The most represented plant is common reed which is an indigenous species for the region. Therefore, CWs are well-fitting the landscape of the region.

\subsection{GIS and analysed data}

Presently, for any spatial analysis, support system, such as the geographic information system (GIS) is irreplaceable, where a multi-layered approach facilitates the decision-making process when a land-use prospect is an issue (Muchová et al., 2016). GIS as a spatially oriented information system enables data processing through operations of collecting, storing, handling, analysis, and presentation, which provides the basis for further decision making. Advantage and specifics of GIS in comparison to other databases are the precise definition of the exact place on the Earth's surface to which these data refer. Within GIS, data are organized in layers for easier handling, where each layer is presenting a set of data of the same type. Input GIS data can be in vector format (point, polyline, polygon), or raster format matrices covering certain space. Each cell of the matrix represents a specific pixel (Benka, 2011).

To fulfil the research aim concerning spatial analyses, free geographic information system (GIS) software QGIS was applied. The main criteria for positioning CWs included following spatial features: distance from a settlement, distance to water bodies, land use, and elevation. For practical reasons, above all satisfying a cost-saving request, a CW had to be in the vicinity of a settlement. For a similar reason, it is important to be close to the watercourse, where purified wastewater will be discharged. For both criteria, the distances of $500 \mathrm{~m}$ and $1000 \mathrm{~m}$ were chosen and mapped. When building any wastewater facility, it must be positioned at a lower altitude than the settlement. That enables the free low-pressure gravitational flow of wastewater through the sewage network which finishes in the wastewater treatment facility. Therefore, the criterion of elevation was chosen and mapped as a belt surrounding each analysed village. Finally, analysing the land cover after the arable land exclusion, abandoned areas and those covered by grass are assumed as favourable land uses. These data were extracted from CORINE land cover (CLC, 2018). All input data were in vector format except data on elevations - Shuttle Radar Topography Mission (SRTM) 30 (NASA JPL, 2013), which were in raster format.

Additional analysis was focused on grading of individual plots, to obtain a degree of favourability. For this purpose, a system of scoring was set, where points were assigned for each plot according to a level of favourability, i.e. the least favourable - 2 points, less favourable -3 points, moderately favourable -4 points, favourable -5 points

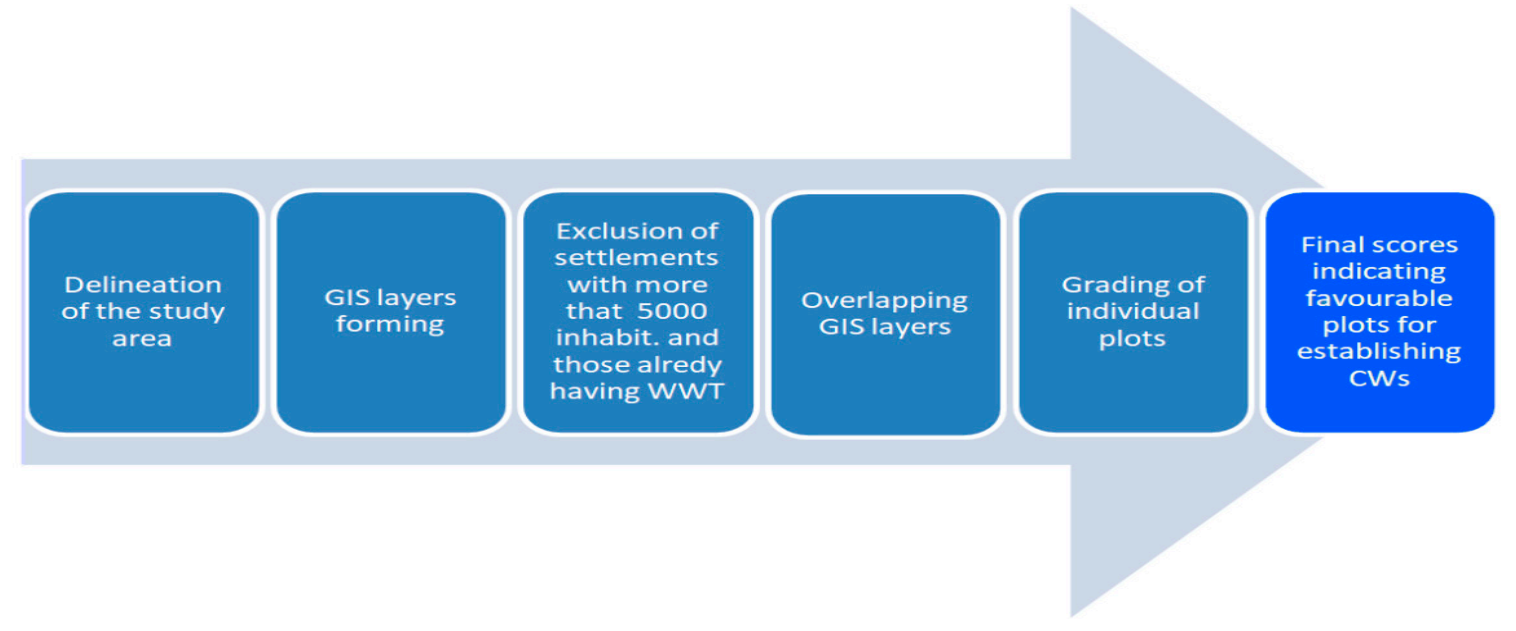


and very favourable - 6 points. For each criterion, there were 3 possibilities for grading: 2 points for more favourable, 1 point for less favourable and 0 points for unfavourable. Namely, distances of $500 \mathrm{~m}$ from settlement and watercourse were assigned to 2 points, and 1 point if the distance is within $500-1,000 \mathrm{~m}$. Complete schematic modelling workflow, of the processes applied in the paper, is shown in Fig. 2.

\section{Results and discussion}

After delineation of the study area, GIS layers were formed, where each layer presents one criterion: distances from the settlement (Fig. 3), distances from watercourse (Fig. 4), land use according to the CORINE land cover (CLC) (https://land.copernicus.eu/ pan-european/corine-land-cover) (Fig. 5) and elevation SRTM 30. Concerning elevation, all settlements were at the same elevation in comparison to the adjacent area or higher, and therefore this criterion was not further analysed. As for CLC, the analyses were performed only from the attribute tables and were not presented in maps. Finally, all layers were overlapped to form the final map. On this map settlements with more than 5,000 inhabitants were excluded, settlements which have already been connected to centralized wastewater treatment facilities and those already having installed some type of wastewater treatment. Further analysis was orientated towards grading of individual plots, to obtain a degree of favourability. For this purpose, a system of scoring was set, where points were assigned for each plot according to a level of favourability (Table 1). For each criterion, there were 3 possibilities for grading: 2 points for more favourable, 1 point for less favourable and 0 points for unfavourable. Namely, distances of $500 \mathrm{~m}$ from settlement and

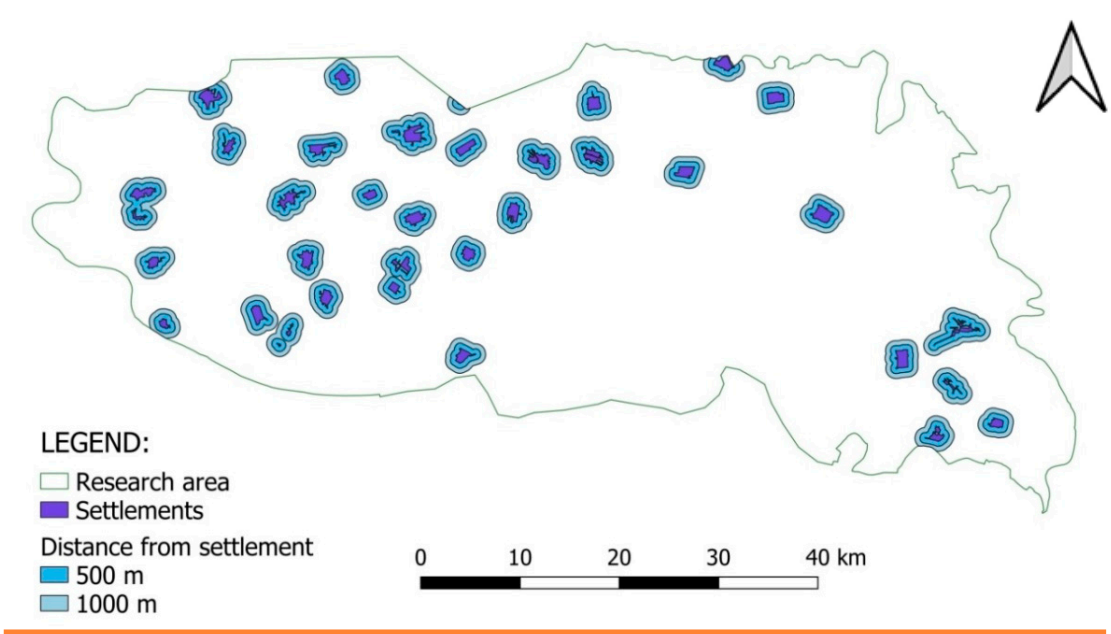

Figure 3 Distance from settlement within the South Bačka District, Republic of Serbia

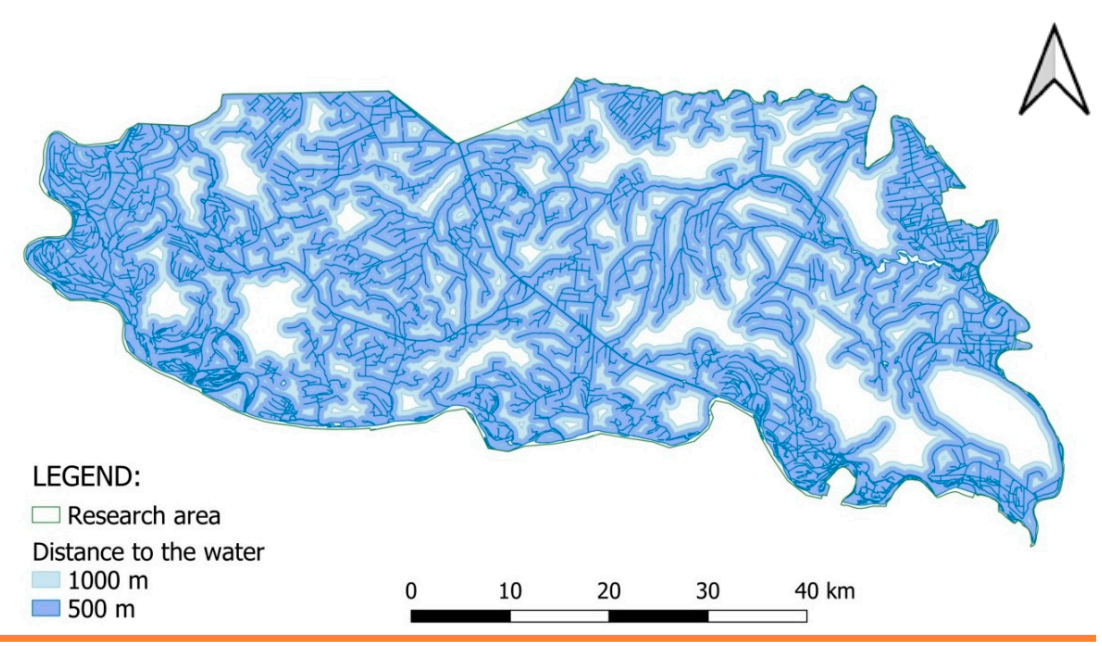

Figure 4 Distance to water bodies within the South Bačka District, Republic of Serbia

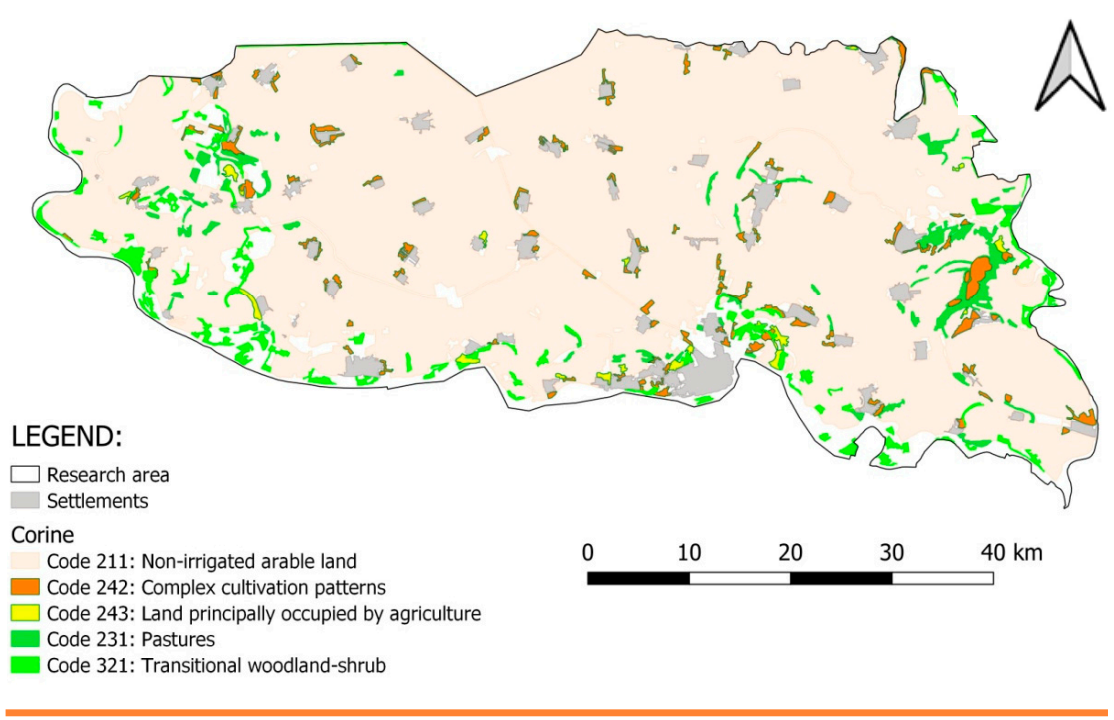

Figure 5 Land use within the South Bačka District, Republic of Serbia Source: CLC, 2018 


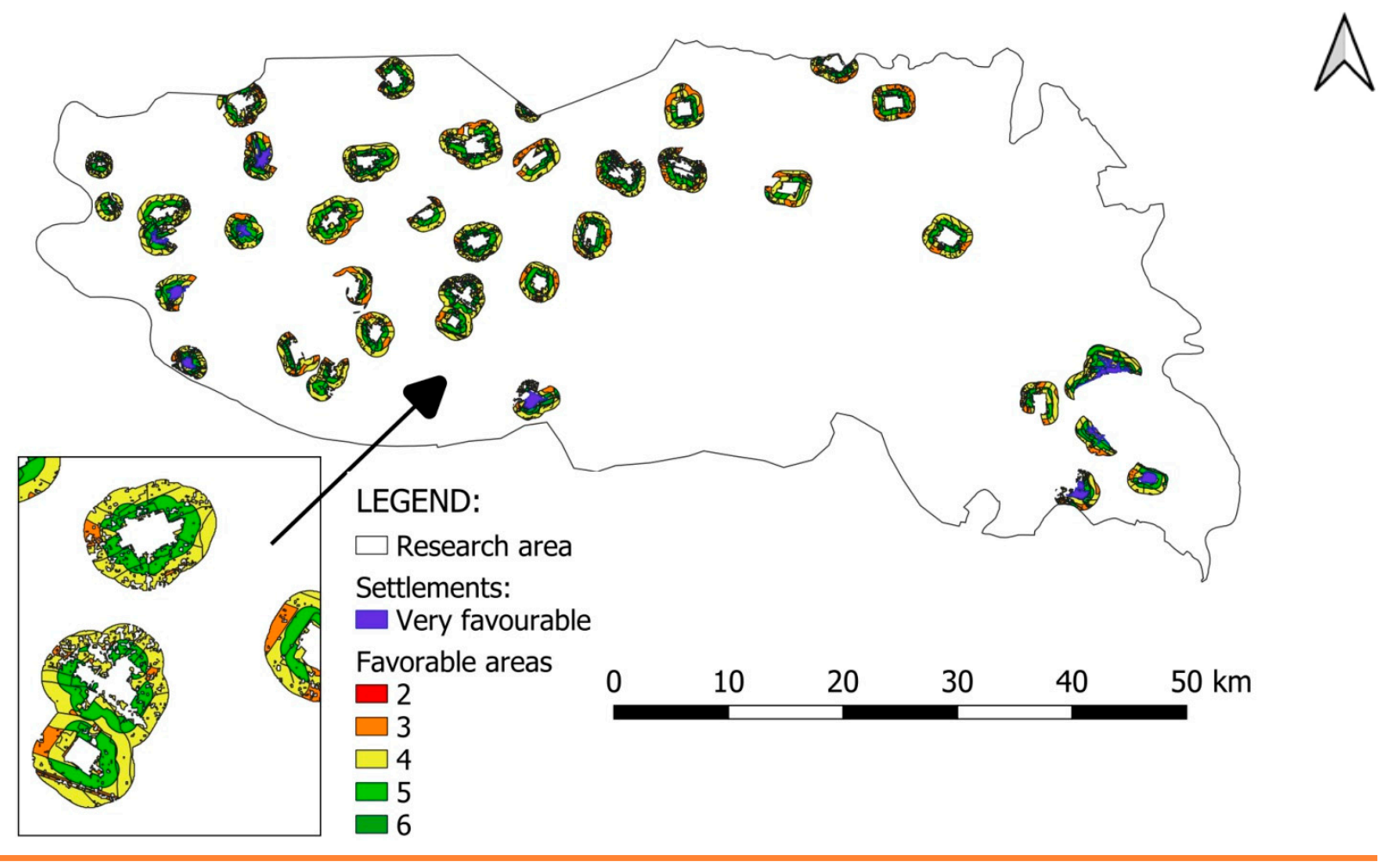

Figure 6

Favourable plots for establishing CWs within the South Bačka District, Republic of Serbia

watercourse were assigned to 2 points, and 1 point if the distance is within 500-1,000 m. Additionally, according to CLC pastures were chosen as favourable areas (code 231) and transitional woodland/shrub (code 324) for which 2 points were assigned. Less favourable areas where 1 point was assigned, were: land principally occupied by agriculture, with significant areas of natural vegetation (code 243), complex cultivation patterns (code 242) and non-irrigated arable land (code 211) (Fig. 5). For this criterion, unfavourable areas were excluded and therefore there was no chance to assign one point to a single plot.

Upon overlapping GIS layers for distances from watercourse and settlement and the land-use layer, the final map was obtained, with grading incorporated. Fig. 6 presents the final result on favourability for positioning
CWs in the surrounding area of small settlements within the South Bačka District, Republic of Serbia. According to it, very favourable plots are determined in the vicinity of ten settlements (marked blue in Fig. 6): Bođani, Deronje, Mali Bač, Bačko Novo Selo, Plavna, Čelerevo, Vilovo, Mošorin, Gardinovci and Lok.

\section{Conclusions}

The problem of untreated wastewater is still present in the South Bačka District, Republic of Serbia, concerning smaller settlements. Thus, this examination focuses upon finding the most favourable locations for positioning CWs in the vicinity of settlements. GIS analyses and further grading of plots revealed that 26,215.32 ha are to some extent favourable for the mentioned purpose. Therefore, the examination proved that in the vicinity of

Table 1 Evaluating plot favourability for positioning CWs

\begin{tabular}{|c|c|c|c|}
\hline $\begin{array}{l}\text { Character of the area upon favourability for } \\
\text { positioning CWs }\end{array}$ & Points & $\begin{array}{l}\text { Number of separate } \\
\text { plots }\end{array}$ & $\begin{array}{c}\text { Area } \\
\text { (ha) }\end{array}$ \\
\hline The least favourable & 2 & 12 & 21.09 \\
\hline Less favourable & 3 & 260 & $3,757.32$ \\
\hline Moderately favourable & 4 & 470 & $13,897.34$ \\
\hline Favourable & 5 & 182 & $8,207.77$ \\
\hline Very favourable & 6 & 22 & 331.80 \\
\hline Total & & & $26,215.32$ \\
\hline
\end{tabular}


35 villages in the South Bačka District, there are spatial preconditions for establishing CWs. The obtained results have fulfilled the basic spatial preconditions. However, further analyses are necessary to be performed for precise positioning of each CW location, taking into account land ownership criterion.

Additionally, the same process could be applied to the whole territory of the Vojvodina Province, covering all its districts. Moreover, it could be utilised even further across the Pannonian Plain stretching to the neighbouring countries (parts of Austria and Slovakia, whole Hungary, and partly Croatia and Romania) since natural features of the terrain and settlements' structure are similar.

\section{Acknowledgments}

The research was funded by the Ministry of Education, Science and Technological Development of the Republic of Serbia (Agreement No. 451-03-68/2020-14/ 200117).

\section{References}

Benka, P. (2011). Effects of restructuring of land territory by consolidation on the plot suitability for agricultural production, In I. Aleksic (Ed.), Professional Practice and Education in Geodesy and Related Fields (pp. 348-355). Faculty of Civil Engineering, University of Belgrade.

CLC - (c) European Union, Copernicus land Monitoring Service (2018). Corine Land Cover [Data set]. European Environmental Agency (EEA).

https://land.copernicus.eu/pan-european/corine-land-cover

Dalmacija, B. (Ed) (2010). Basis of wastewater management. University of Novi Sad, Faculy of sciences. Department of chemistry, biochemistry and environmental protection (in Serbian)

Directive 2000/60/EC of the European Parliament and of the Council of 23 October 2000 establishing a framework for Community action in the field of water policy. Official Journal of the European Union, 327, 1-73.

Directive 2013/39/EU of the European parliament and of the council of 12 August 2013 amending Directives 2000/60/ EC and 2008/105/EC as regards priority substances in the field of water policy. Official Journal of the European Union, 226, 1-17.

Directive 1991/271/EEC of 21 May 1991 concerning urban waste-water treatment. Official Journal of the European Union, 135, (40-52).

González, H. F., Corvea Porras, J. L., de Bustamante Gutiérrez, I., LaMoreaux, J. W., \& Molerio-Leon, L. F. (2013). Management of Water Resources in Protected Areas: An Introduction. In H. F. González, J. L. Corvea Porras, I. de Bustamante Gutiérrez, \& J. W. LaMoreaux (Eds.), Management of Water Resources in Protected Areas (pp. v-viii). Springer.

Gorito, A. M, Ribeiro, A. R., Almeida, C. M. R., \& Silva, A. M. T. (2017). A review on the application of constructed wetlands for the removal of priority substances and contaminants of emerging concern listed in recently launched EU legislation. Environ Pollution., 227, 428-443.

https://doi.org/10.1016/j.envpol.2017.04.060
Josimov-Dundjerski, J., Belić, A., Salvai, A., \& Grabić, J. (2013). Age of Constructed Wetland and Effects of Wastewater Treatment. Bulgarian Journal of Agricultural Science, 19(4), 679684. http://www.agrojournal.org/19/04-08.pdf

Josimov-Dundjerski, J., Savić, R., Belić, A., Salvai, A., \& Grabić, J. (2015a). Sustainability of Constructed Wetland Based on the Characteristics in Effluent. Agriculture Journals, Soil \& Water Resources, 10(2), 114-120.

http://www.agriculturejournals.cz/publicFiles/152326.pdf

Josimov-Dunđerski, J., Grabić, J., \& Belić, A. (2015b). Constructed wetlands in protection of water resources in Vojvodina. Annals of agronomy, 39(1), 24-32.

http://scindeks.ceon.rs/article.aspx?artid $=0546-82641501024 \mathrm{~J}$

Kolaković, S., Vujović, S., Jeftenić, G., Kolaković, S., \& Mašić, B. (2013). Sanitation and waste water management in Vojvodina (Serbia). The $6^{\text {th }}$ PSU-UNS International Conference on Engineering and Technology (ICET-2013), Novi Sad, Serbia, University of Novi Sad, Faculty of Technical Sciences, 1-6.

Muchová,Z., Leitmanová, M., \& Petrovič, F. (2016). Possibilities of optimal land use as a consequence of lessons learned from land consolidation projects (Slovakia). Ecological Engineering, 90, 294-306. https://doi.org/10.1016/j.ecoleng.2016.01.018

NASA JPL (2013). NASA Shuttle Radar Topography Mission Global 3 arc second [Data set]. NASA EOSDIS Land Processes DAAC. https://doi.org/10.5067/MEaSUREs/SRTM/SRTMGL3.003

Nikolić, L J., Maksimović, I., Džigurski, D. \& Putnik-Delić, M. (2015). The content of microelements (Cu i Zn) in reed (Phragmites australis (Cav.) Trin. ex Steud.) of the constructed wetland system. Contemporary Problems of Ecology, 8(4), 493498. https://doi.org/10.1134/S1995425515040113

SEPA - Serbian Environmental Protection Agency (2019). Study in the field of management of municipal waste waters in local municipalities on the territory of the republic of Serbia. Ministry of environmental protection of the Republic of Serbia. JN 1.2.4/19 (in Serbian)

Statistical Office of the Republic of Serbia (2014). Comparative overview of the number of population in 1948, 1953, 1961, 1971, 1981, 1991, 2002 and 2011 [Data by settlements].

Stefanakis, A. I. (2019). The Role of Constructed Wetlands as Green Infrastructure for Sustainable Urban Water Management. Sustainability, MDPI, 11(24), 1-19.

https://doi.org/10.3390/su11246981

United Nations. (2015). Transforming Our World, the 2030 Agenda for Sustainable Development. General Assembly Resolution A/RES/70/1. http://www.un.org/ga/search/view doc.asp?symbol=A/RES/70/1\&Lang=E

Vymazal, J. (2005). Horizontal Subsurface Flow and Hybrid Constructed wetland System for Wastewater Treatment. Ecological Engineering, 24, 478-490. https://doi.org/10.1016/j.ecoleng.2005.07.010 